\title{
Effects of Magnetic Field on Athermal and Isothermal Martensitic Transformations in Fe-Ni-Cr Alloys ${ }^{\dagger}$
}

\author{
Tomoyuki Kakeshita*, Yoshihiro Sato*+†, Toshio Saburi*, \\ Ken'ichi Shimizu**, Yuki Matsuoka***+† and Koichi Kindo*** \\ *Department of Materials Science and Engineering, Faculty of Engineering, Osaka University, \\ 2-1, Yamada-oka, Suita, Osaka 565-0871, Japan \\ **Advanced Materials Science Research and Development Center, Kanazawa Institute of Technology, \\ 3-1 Yatsukaho, Matto, Ishikawa 924-0838, Japan \\ *** Research Center for Materials Science at Extreme Conditions, Osaka University, \\ 1-3, Machikaneyama-cho, Toyonaka, Osaka 560-8531, Japan
}

\begin{abstract}
Effects of magnetic field on the athermal martensitic transformation in an $\mathrm{Fe}-31.4 \mathrm{Ni}-0.5 \mathrm{Cr}$ alloy (mass\%), whose $M_{s}$ temperature is about $183 \mathrm{~K}$, and on the isothermal one in an $\mathrm{Fe}-25.0 \mathrm{Ni}-4.0 \mathrm{Cr}$ alloy (mass\%), whose nose temperature is about $143 \mathrm{~K}$, have been examined by measuring magnetic field susceptibility and magnetization, and by observing optical microstructure, applying pulsed high magnetic fields up to $31 \mathrm{MA} / \mathrm{m}$. The obtained results were the following: The austenitic state in the $\mathrm{Fe}-31.4 \mathrm{Ni}-0.5 \mathrm{Cr}$ alloy is ferromagnetic, whereas that in the $\mathrm{Fe}-25.0 \mathrm{Ni}-4.0 \mathrm{Cr}$ alloy is spin glass. Even in the latter alloy, martensitic transformation is induced instantaneously under pulsed magnetic fields higher than a critical one over a wide temperature range, as in the former alloy. This result suggests that the originally isothermal process of martensitic transformation changes to the athermal one under high magnetic fields. Optical microscopy showed that isothermal martensite plates of the $\mathrm{Fe}-25.0 \mathrm{Ni}-4.0 \mathrm{Cr}$ alloy under no magnetic field grow gradually during isothermal holding. Moreover, morphology of the magnetic field-induced martensites of both alloys was almost the same as that of thermally-induced ones, irrespective of the formation temperature. A thermodynamic calculation for the critical magnetic field vs temperature relation has been done for both the alloys by using an equation previously proposed, and the calculated relations are all in good agreement with the experimental ones in the wide temperature range examined. The present results are almost the same as those in the study previously examined on the athermal and isothermal martensitic transformations in $\mathrm{Fe}-\mathrm{Ni}$-Mn alloys under pulsed high magnetic fields.
\end{abstract}

(Received September 11, 1998; In Final Form November 16, 1998)

Keywords: martensitic transformation, isothermal process, athermal process, morphology, iron-nickel-chrominum alloy, time-temperature-transformation diagram, C-curve, nose temperature, magnetic field inducement, critical magnetic field, spin glass, atom cluster, Boltzmann factor

\section{Introduction}

Martensitic transformations are well known to be classified into two groups, with respect to kinetics of martensitic transformation, isothermal and athermal ones. The former transformation has a definite transformation start temperature, $M_{\mathrm{s}}$, and occurs instantaneously when the $M_{\mathrm{s}}$ temperature is reached on cooling, while the latter one does not have a definite transformation temperature but occurs after some finite incubation time during isothermal holding ${ }^{(1)}$. Until now, there have been many studies on the isothermal process in $\mathrm{Fe}-\mathrm{Ni}-\mathrm{Mn}$ alloys ${ }^{(2)-(4)}$.

Recently, we studied the effect of magnetic field on the

$\dagger$ A part of this paper was originally read at the Annual Spring Meeting of the Japan Institute of Metals, Yokohama, (1993).

\# Graduate Student at Suita Campus, Osaka University. Present Address: Nippon Steel Corporation, Quality Control Division, 5-3, Tokai-cho, Tokai, Aichi 476-0088, Japan.

$\mathrm{H+T}$ Graduate Student at Toyonaka Campus, Osaka University. Present Address: Advanced Science Research Center, Japan Atomic Energy Research Institute, 2-4 Shirakatashirane, Tokai-mura, Naka-gun, Ibaraki 319-1195, Japan. athermal and isothermal martensitic transformations in $\mathrm{Fe}-\mathrm{Ni}-\mathrm{Mn}$ alloys ${ }^{(5)}$ and found that even in the $\mathrm{Fe}-\mathrm{Ni}-\mathrm{Mn}$ alloy which is known to exhibit the isothermal martensitic transformation, a high magnetic field induces an instantaneous martensitic transformation, i.e., the athermal martensitic transformation occurs under a high magnetic field, as in another $\mathrm{Fe}-\mathrm{Ni}-\mathrm{Mn}$ alloy exhibiting an athermal martensitic transformation. This means that isothermal process of martensitic transformation changes to the athermal process of martensitic transformation, suggesting that the two transformation processes are closely related to each other and their difference is not intrinsic but they may be explained by one basic rule. On the basis of this finding, we constructed a phenomenological theory ${ }^{(6)}$, which gives a unified explanation for the two transformation processes. However, it is not certain whether or not the above experimental results, which are important to confirm the propriety of the theory constracted, have generality for other alloys exhibiting an athermal and/or isothermal martensitic transformation. As for such materials, an $\mathrm{Fe}-\mathrm{Ni}-\mathrm{Cr}$ alloy is suitable because it is also well known to exhibit an athermal and/or isothermal martensitic transformation, depending on its 
alloy composition ${ }^{(7)}$.

The purpose of the present study, therefore, is to examine the effects of magnetic field on the athrermal and isothermal martensitic transformations in $\mathrm{Fe}-\mathrm{Ni}-\mathrm{Cr}$ alloys in the following way: The first is to examine athermal and isothermal characteristics in $\mathrm{Fe}-\mathrm{Ni}-\mathrm{Cr}$ alloys, such as $M_{\mathrm{s}}$ and nose temperatures, volume change associated with martensitic transformation, spontaneous magnetization, magnetic susceptibility and morphology of martensites. The second is to obtain critical magnetic fields for inducing martensites at various temperatures in those alloys by magnetization measurements under pulsed magnetic fields up to $31 \mathrm{MA} / \mathrm{m}$. The last is to calculate the critical magnetic field vs temperature relations in those alloys by putting the measured physical quantities into the equation previously proposed, which evaluates the magnetic field dependence of the transformation temperature, and is to compare the calculated relations with the experimentally measured ones.

\section{Experimental Procedure}

The alloys examined were $\mathrm{Fe}-31.4 \mathrm{Ni}-0.5 \mathrm{Cr}$ and $\mathrm{Fe}-$ $25.0 \mathrm{Ni}-4.0 \mathrm{Cr}$ alloys (mass\%), which exhibit the athermal and isothermal martensitic transformations, respectively, and were produced by an argon arc-melting method. The alloys will be labeled A and B alloys, respectively, for simplicity. The ingots thus obtained were hot-forged, homogenized at $1373 \mathrm{~K}$ for $8.64 \times 10^{4} \mathrm{~s}$ and hot-rolled into sheets. From the sheets, specimens were cut into various sizes as follows depending on the kinds of measurements: $3 \mathrm{~mm} \times 6 \mathrm{~mm} \times 0.4 \mathrm{~mm}$ for electrical resistivity measurements of the A alloy to obtain its $M_{\mathrm{s}}$ temperature, $3 \mathrm{~mm} \times 6 \mathrm{~mm} \times 0.4 \mathrm{~mm}$ for the isothermal holding measurements of the B alloy to fabricate its TTT diagram, $14 \mathrm{~mm} \times 18 \mathrm{~mm} \times 1 \mathrm{~mm}$ for the $\mathrm{X}$-ray diffraction measurements of the A alloy to obtain its volume change associated with martensitic transformation, $3 \mathrm{~mm} \times 12$ $\mathrm{mm} \times 0.4 \mathrm{~mm}$ for the spontaneous magnetization, 3 $\mathrm{mm} \times 3 \mathrm{~mm} \times 0.4 \mathrm{~mm}$ for the magnetic field susceptibility and $3 \mathrm{~mm} \times 5 \mathrm{~mm} \times 0.3 \mathrm{~mm}$ for the forced volume magnetostriction measurements for both the alloys to know their magnetic properties and $3 \mathrm{~mm} \times 12 \mathrm{~mm} \times 0.4 \mathrm{~mm}$ for the magnetization measurements of both the alloys under pulsed magnetic fields up to $31 \mathrm{MA} / \mathrm{m}$. The specimens were finally solution-treated at $1273 \mathrm{~K}$ in silica capsules filled with argon, and then quenched into water. After the magnetization measurements, morphology of the martensite was observed by optical microscopy. The etchant used for the observation was a $35 \%$ sodium pyrosulfite solution. The magnetic field susceptibility, forced volume magnetostriction were measured by a Faraday type method and Fabry-Pérot interferometry method, respectively, and details of these measurements were already described elsewhere ${ }^{(8)}$. Magnetization measurements were carried out at Research Center for Matrerials Science at Extreme Conditions, Osaka University. The details of the ultra high magnetic field instrument have been reported elsewhere ${ }^{(9)}$. Chemical analysis of the alloy compositions were carried out by using the rest part of the $0.4 \mathrm{~mm}$ thick sheets, which were subjected to the same heat-treatment as above in order to avoid a discrepancy in composition between the chemically analyzed and experimentally used specimens. The alloy compositions thus analyzed are the ones mentioned at the beginning of this section.

\section{Results}

1. TTT diagram, volume change, spontaneous magnetization, magnetic field susceptibility and forced volume magnetostriction

Prior to measurements under pulsed high magnetic fields, some physical properties of A and B alloys have been examined, such as transformation temperature, TTT diagram, lattice parameter, spontaneous magnetization, magnetic field susceptibility and forced volume magnetostriction. First of all, the electrical resistivities have been measured as a function of temperature for both the alloys in the range between 293 and 77 K. Figure 1 shows the electrical resistivity of the A alloy as a function of temperature. It should be noted that an instantaneous decrease in resistivity was recognized at $183 \mathrm{~K}$, meaning that this alloy certainly exhibits an athermal transformation at $183 \mathrm{~K}$, which corresponds to the $M_{\mathrm{s}}$ temperature of the alloy. On the other hand, such an instantaneous change is not recognized for the B alloy. Then, the B alloy has been isothermally held at several temperatures between 4.2 and $293 \mathrm{~K}$. The typical TTT diagram, which represents $0.1 \%$ volume fraction of martensite, is shown with the closed circles connected by the solid line in Fig. 2 , where the volume fraction of martensite was obtained by optical microscopy observation and magnetization measurement, as in a previous study ${ }^{(10)}$. It should be noted in the figure that the $T T T$ diagram clearly forms a Ccurve whose nose temperature is about $143 \mathrm{~K}$, indicating that the alloy certainly exhibits an isothermal martensitic

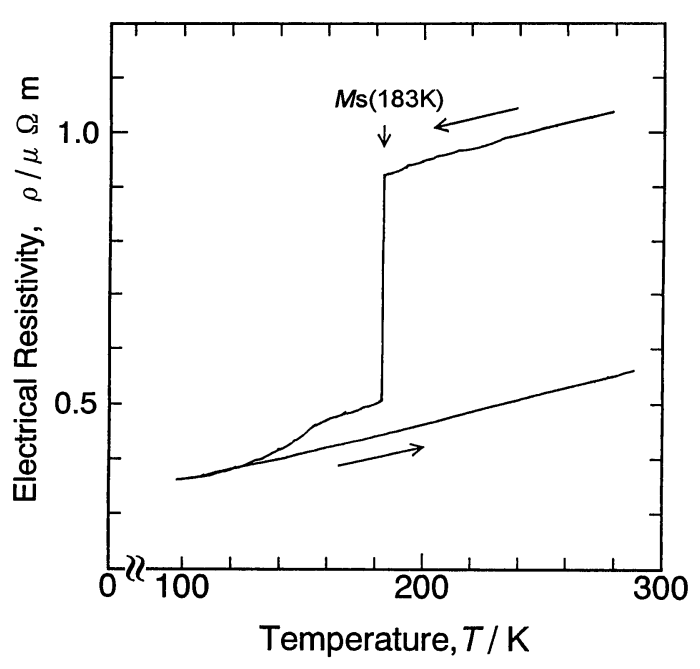

Fig. 1 Electrical resistivity as a function of temperature in $\mathrm{Fe}-31.4 \mathrm{Ni}-$ $0.5 \mathrm{Cr}$ alloy. 
transformation.

During the isothermal holding measurement in the B alloy, we found by optical microscopy that martensite plates grow gradually during isothermal holding under

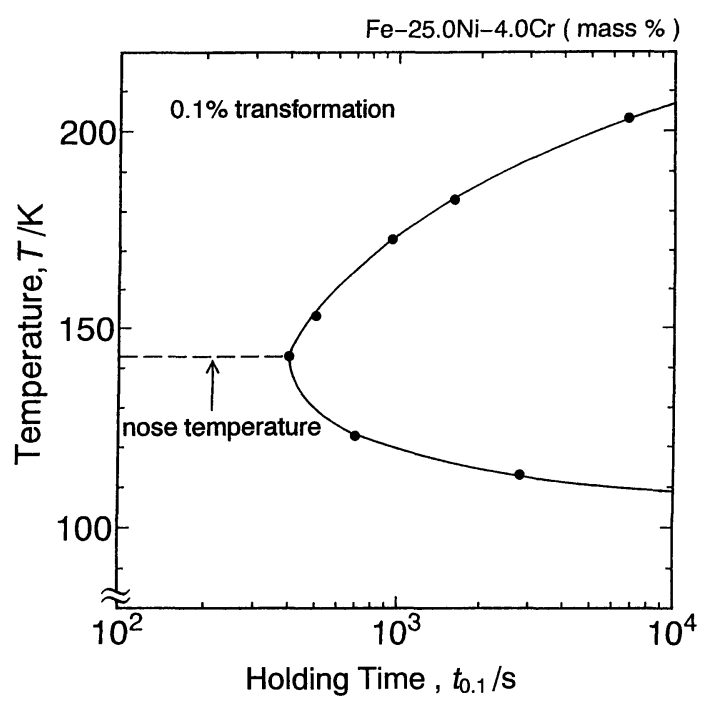

Fig. $2 T T T$ diagram of the isothermal martensitic transformation in an $\mathrm{Fe}-25.0 \mathrm{Ni}-4.0 \mathrm{Cr}$ (mass \%) alloy. no magnetic field, as shows in Fig. 3(a) to (d).

Volume change associated with martensitic transformation for the A alloy and an $\mathrm{Fe}-25.0 \mathrm{Ni}-3.0 \mathrm{Cr}$ alloy (mass\%), as a substitute for the B alloy, have been calculated from their lattice parameters of the austenitic and martensitic phases measured by X-ray diffraction with a cold stage. The volume change associated with martensitic transformation will be used to calculate the relation between the critical magnetic field and temperature, which will be described later. The reason for using the $\mathrm{Fe}$ $25.0 \mathrm{Ni}-3.0 \mathrm{Cr}$ alloy as a substitute is that the alloy has nearly the same composition as the B alloy and also exhibits an isothermal transformation. Moreover, the fraction of martensite in the substitute alloy is enough to be detected by X-ray diffraction, although that in the B alloy is not enough in spite of the long isothermal holding. However, the substitute alloy was not used throughout the present work, because the incubation time needed for the martensite formation in the substitute alloy is much shorter than that in the B alloy, and therefore the fraction of martensite in the $\mathrm{Fe}-25.0 \mathrm{Ni}-3.0 \mathrm{Cr}$ alloy largely increases during specimen setting at a temperature before applying the magnetic field. Such a large increase is inappropriate for examining only the influence of magnetic
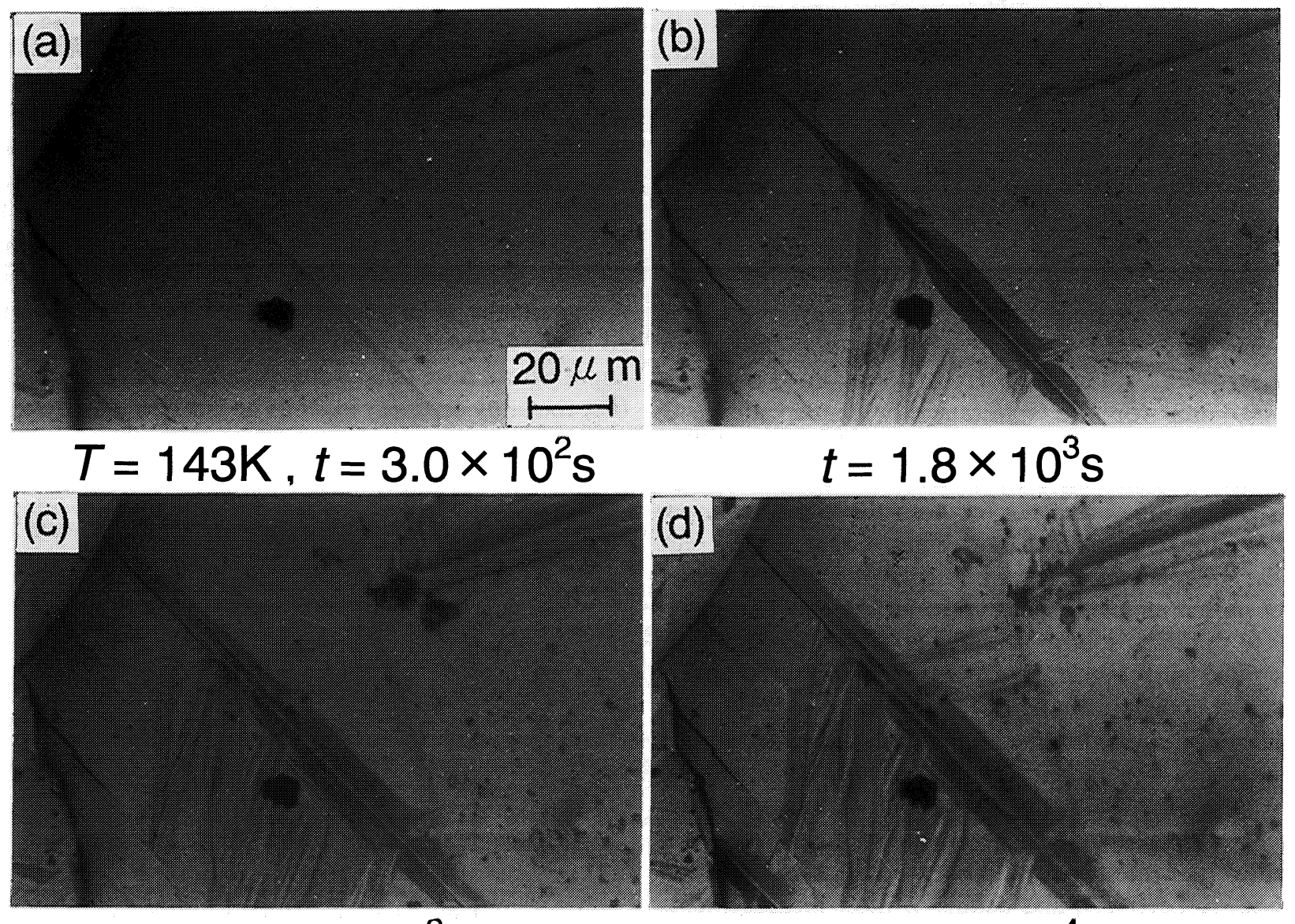

$$
t=9.0 \times 10^{2} \mathrm{~s}
$$

$$
t=1.3 \times 10^{4} \mathrm{~s}
$$

Fig. 3 In-situ optical micrographs taken at room temperature after the isothermal holding at $143 \mathrm{~K}$, showing the gradual growth of a martensite plate in an $\mathrm{Fe}-25.0 \mathrm{Ni}-4.0 \mathrm{Cr}$ (mass\%) alloy. Holding time, $t$, at $143 \mathrm{~K}$ is inscribed beneath each photograph. 
field on the isothermal martensitic transformation. The volume change thus calculated are shown in Fig. 4 as a function of temperature for the $\mathrm{A}$ alloy and the substitute of the B alloy. As known from the figure, the volume change for the A alloy decreases slightly, but that for the substitute of the B alloy increases with decreasing temperature. The former decrease is attributed to the Invar effect if we consider the fact that coefficient of linear expansion of the austenitic phase in the $\mathrm{A}$ alloy is quite small $\left(8.74 \times 10^{-6}\right)$, as in a previous $\mathrm{Fe}-29.9$ at $\% \mathrm{Ni}$ Invar alloy ${ }^{(10)}$.

Magnetization in the austenitic state of the two alloys under low magnetic field has been measured. The spontaneous magnetization per atom is shown as a function of temperature in Fig. 5. It is found that the austenitic states of A and B alloys are ferromagnetic from the existence of spontaneous magnetization. However, the temperature dependence of spontaneous magnetization in the B alloy is quite strange; the spontaneous magnetiza-

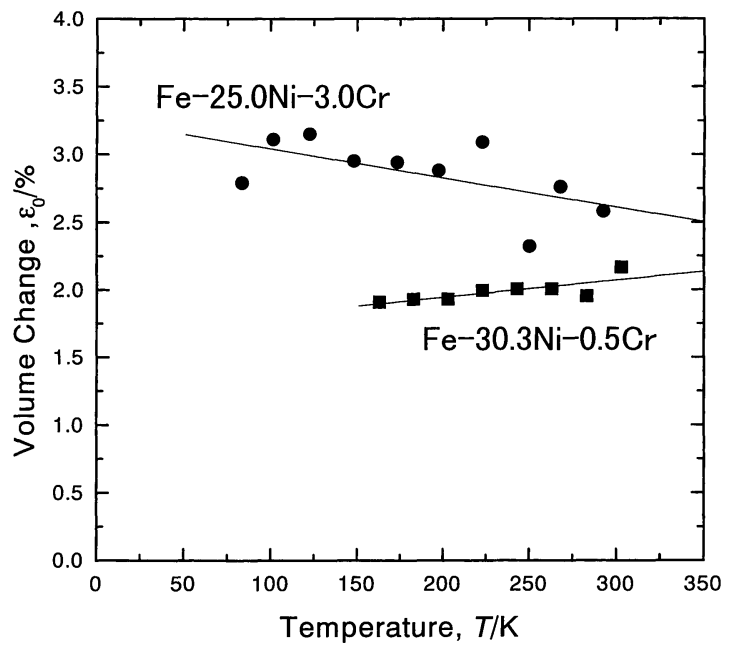

Fig. 4 Volume changes associated with martensitic transformation in $\mathrm{Fe}-31.4 \mathrm{Ni}-0.5 \mathrm{Cr}$ (mass $\%$ ) and $\mathrm{Fe}-25.0 \mathrm{Ni}-4.0 \mathrm{Cr}$ (mass $\%$ ) alloys, plotted as a function of temperature.

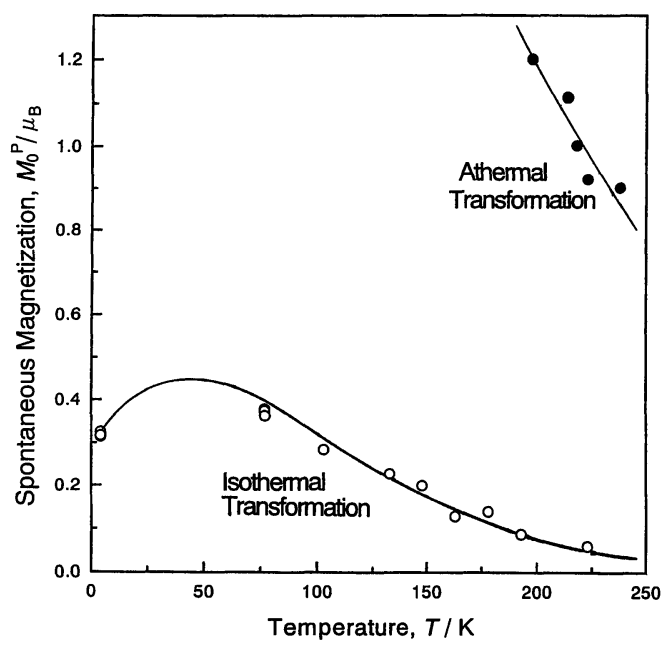

Fig. 5 Spontaneous magnetizations per atom in the austenitic state for $\mathrm{Fe}-31.4 \mathrm{Ni}-0.5 \mathrm{Cr}$ (mass\%) and $\mathrm{Fe}-25.0 \mathrm{Ni}-4.0 \mathrm{Cr}$ (mass\%) alloys, plotted as a function of temperature. tion at $4.2 \mathrm{~K}$ is slightly lower than that at $77 \mathrm{~K}$, being different from those of normal ferromagnetic materials. Then, in order to know the magnetic state of the B alloy in more detail, magnetic field susceptibility, $\chi$, of the alloy has been measured by a Faraday type magnetic balance method, applying the low static magnetic field of $7.9 \times 10^{-2} \mathrm{MA} / \mathrm{m}$. A typical $\chi-T$ curve is shown in Fig. 6. It is noted that $\chi-T$ curve has a broad peak around 77 $\mathrm{K}$. The curve is reversible in the temperature range measured. This suggests that the austenite of the alloy is in $s$ spin glass (ferromagnetic and antiferromagnetic states coexist), as previously reported in the $\mathrm{Fe}-\mathrm{Ni}-\mathrm{Mn}$ alloy ${ }^{(5)}$.

Spontaneous magnetizations of the martensitic state in both alloys are obtained by referring to the SlaterPauling curve ${ }^{(11)}$. The values for $\mathrm{A}$ and $\mathrm{B}$ alloys are $1.92 \mu_{\mathrm{B}}$ and $2.08 \mu_{\mathrm{B}}$ at $0 \mathrm{~K}$, respectively. We used these values as those for the spontaneous magnetization in measurement temperatures because their Curie temperatures are much higher. Temperature dependences of the forced volume magnetostriction in the austenitic state of both the alloys have been obtained by Fabry-Pérot interferometry with the $\mathrm{He}-\mathrm{Ne}$ laser of $0.6328 \mu \mathrm{m}$ in wavelength, and are shown in Fig. 7. It is to be noted

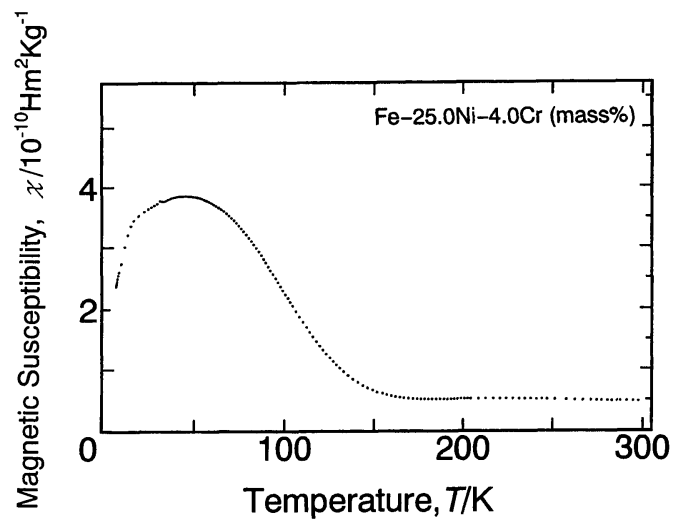

Fig. 6 Magnetic susceptibility as a function of temperature of an $\mathrm{Fe}-$ $25.0 \mathrm{Ni}-4.0 \mathrm{Cr}$ (mass \%) alloy, plotted as a function of temperature.

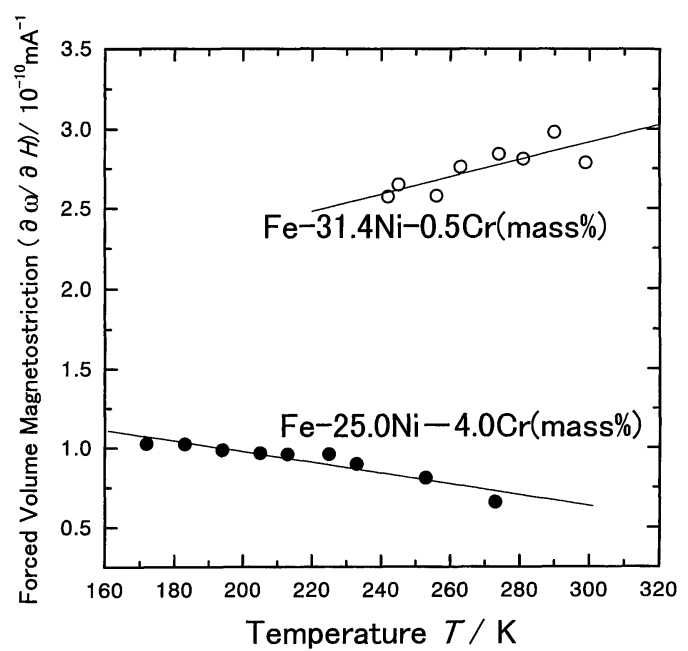

Fig. 7 Forced volume magnetostrictions for $\mathrm{Fe}-31.4 \mathrm{Ni}-0.5 \mathrm{Cr}$ (mass\%) and $\mathrm{Fe}-25.0 \mathrm{Ni}-4.0 \mathrm{Cr}$ (mass\%) alloys, as a function of temperature. 
that the alloys are known to have comparatively large forced volume magnetostriction, whose value is one order larger than that of pure $\mathrm{Ni}$.

\section{Critical magnetic fields for inducing martensites}

Magnetization $M(t)$ has been measured as a function of magnetic field $H(t)$ in one pulse. Typical $M(t)-H(t)$ curves $(M(t)$ represents the magnetization per atom) are shown in Fig. 8(a) and (b), where (a) is for the A alloy at $223 \mathrm{~K}$, which is $40 \mathrm{~K}$ higher than $M_{\mathrm{s}}$ temperature, and (b) is for the B alloy at $4.2 \mathrm{~K}$. In (a), an instantaneous increase in magnetization is recognized at a certain strength of magnetic field (indicating with an arrow), as in previous alloys ${ }^{(5)(10)}$, which exhibits an athermal martensitic transformation (from the analysis of magnetization curve in (a), the time required for the transformation is less than $30 \mu \mathrm{s})$. The certain strength for the abrupt increase in magnetization corresponds to the critical one for inducing the martensitic transformation. It should be noted in (b) that a similar increase in magnetization (indicated with an arrow) occurs in the B alloy. Under no magnetic field, isothermal martensitic transformation was not observed in the alloy for isothermal holding at $4.2 \mathrm{~K}$ even for periods longer than a week. Similar $M-H$ curves were obtained at temperatures higher than $4.2 \mathrm{~K}$. These results suggest that the isothermal process of martensitic transformation changes to an athermal one under high magnetic fields and gives important information on the kinetics of martensitic transformation. Figure 9 shows
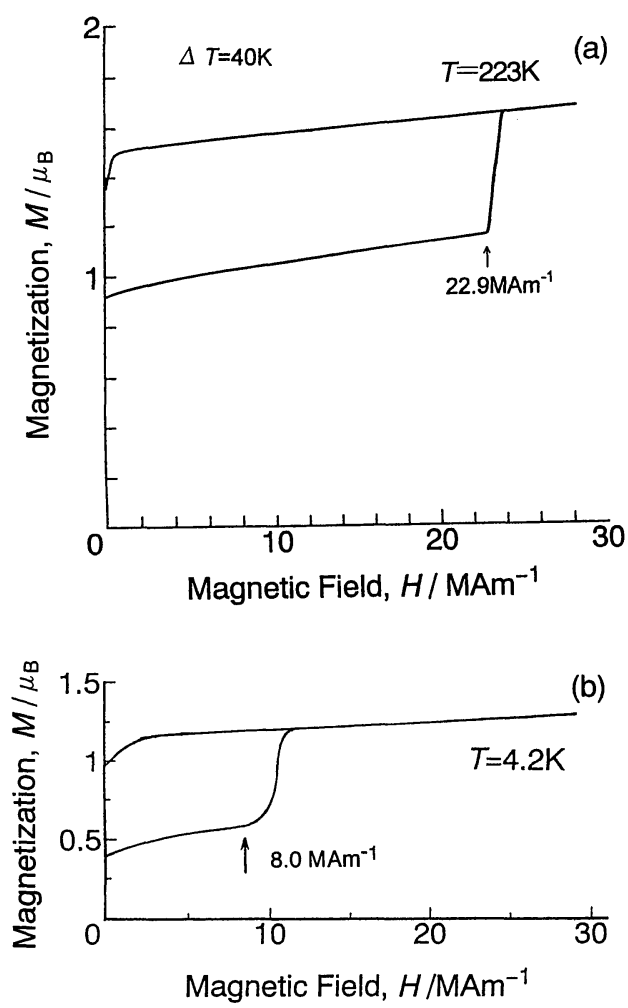

Fig. 8 Magnetization (per atom) vs magnetic field curves of an $\mathrm{Fe}-$ $31.4 \mathrm{Ni}-0.5 \mathrm{Cr}$ (mass \%) alloy at $203 \mathrm{~K}$, (a), and $\mathrm{Fe}-25.0 \mathrm{Ni}-4.0 \mathrm{Cr}$ (mass \%) alloy at $4.2 \mathrm{~K}$, (b), the magnetization increased instantaneously at a critical magnetic field indicated by arrows. the relations between the critical magnetic fields and transformation temperatures (indicated with the solid and open circles) for both $\mathrm{A}$ and $\mathrm{B}$ alloys. As known from the figure, the relation for the $B$ alloy decreases with decreasing temperature. Strictly speaking, the critical magnetic field at $4.2 \mathrm{~K}$ is higher than that at $77 \mathrm{~K}$. The reason is not known yet, but may be due to a spin glass state of the alloy as mentioned before. Similar decrease is observed in the A alloy and previous alloys, which exhibits an athermal martensitic transformation ${ }^{(5)(10)}$. The decrease is linear and temperature extrapolated to zerofield is $M_{\mathrm{s}}$ temperature. These results are quite similar to those of previous $\mathrm{Fe}-\mathrm{Ni}-\mathrm{Mn}$ alloys ${ }^{(5)(6)}$ exhibiting an athermal and/or isothermal martensitic transformation.

\section{Fraction and morphology of magnetic field- induced martensites}

The fraction of magnetic field-induced martensite formed under the magnetic field of $29.4 \mathrm{MA} / \mathrm{m}$ has been calculated in the same method as in the previous study ${ }^{(10)}$. The calculated martensite fractions are shown in Fig. 10.

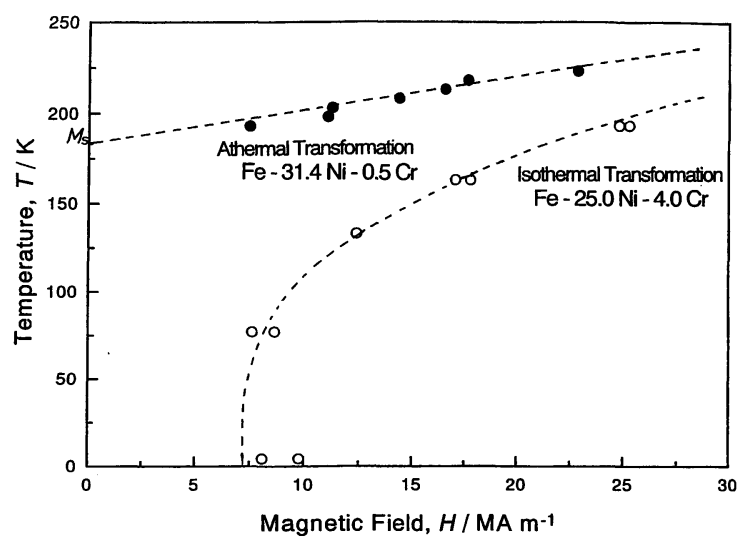

Fig. 9 The relation between critical magnetic field and temperature of $\mathrm{Fe}-31.4 \mathrm{Ni}-0.5 \mathrm{Cr}$ (mass\%) and $\mathrm{Fe}-25.0 \mathrm{Ni}-4.0 \mathrm{Cr}$ (mass\%) alloys, and the dotted lines represent the calculated relations.

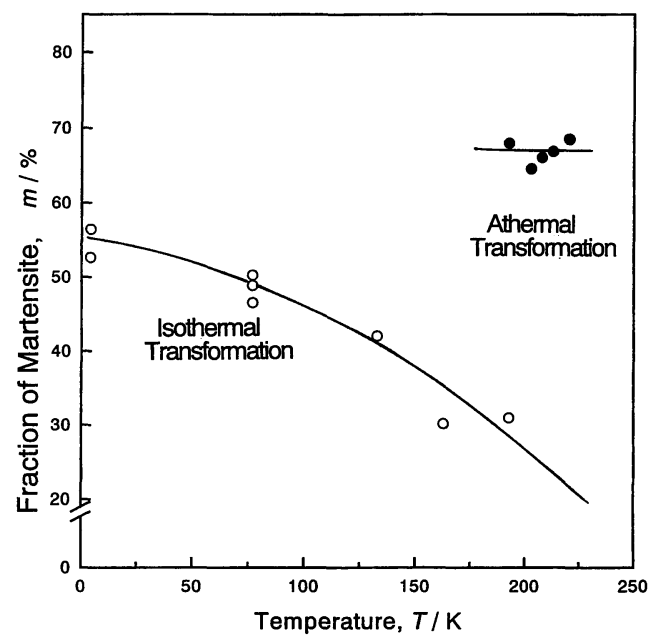

Fig. 10 Fractions of magnetic field-induced martensites in Fe-31.4Ni$0.5 \mathrm{Cr}$ (mass \%) and $\mathrm{Fe}-25.0 \mathrm{Ni}-4.0 \mathrm{Cr}$ (mass $\%$ ) alloys under the magnetic field of $29.4 \mathrm{MA} / \mathrm{m}$, as a function of temperature. 

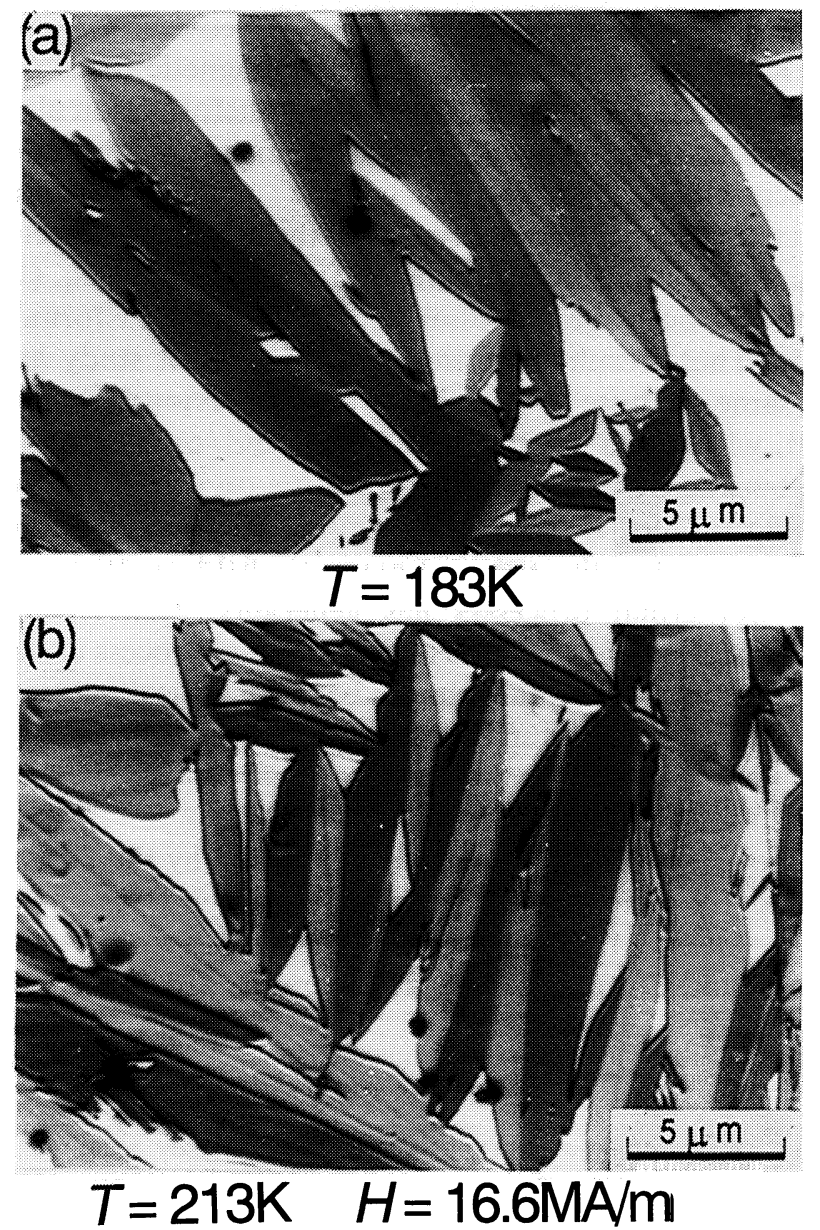

Fig. 11 Optical micrographs of thermally-induced martensites, (a), and magnetic field-induced martensites, (b), in an $\mathrm{Fe}-31.4 \mathrm{Ni}-0.5 \mathrm{Cr}$ (mass \%) alloy.

It is noted from the figure that the martensite fraction for the B alloy increases with decreasing temperature although no martensites is observed even after long isothermal holding longer than a week at $4.2 \mathrm{~K}$ under no magnetic field, while that for the A alloy is almost independent of temperature.

Figures 11 and 12 show optical micrographs of thermally- and magnetic field-induced martensites in A and B alloys. (a) in Fig. 11 and (a) in Fig. 12 are for thermallyinduced martensites, and formation temperature and magnetic field are inscribed beneath each photograph. It should be noted from the figures that morphologies of the magnetic field-induced martensites in both the alloys are similar to that of thermally-induced martensites, irrespective of the formation temperature. These results are also quite similar to those of previous $\mathrm{Fe}-\mathrm{Ni}-\mathrm{Mn}$ alloys ${ }^{(5)(6)}$ exhibiting an athermal and/or isothermal martensitic transformation.

\section{Discussion}

The effect of magnetic field on athermal martensitic transformations has previously been proposed to consist of a combination of three effects; magnetostatic, high
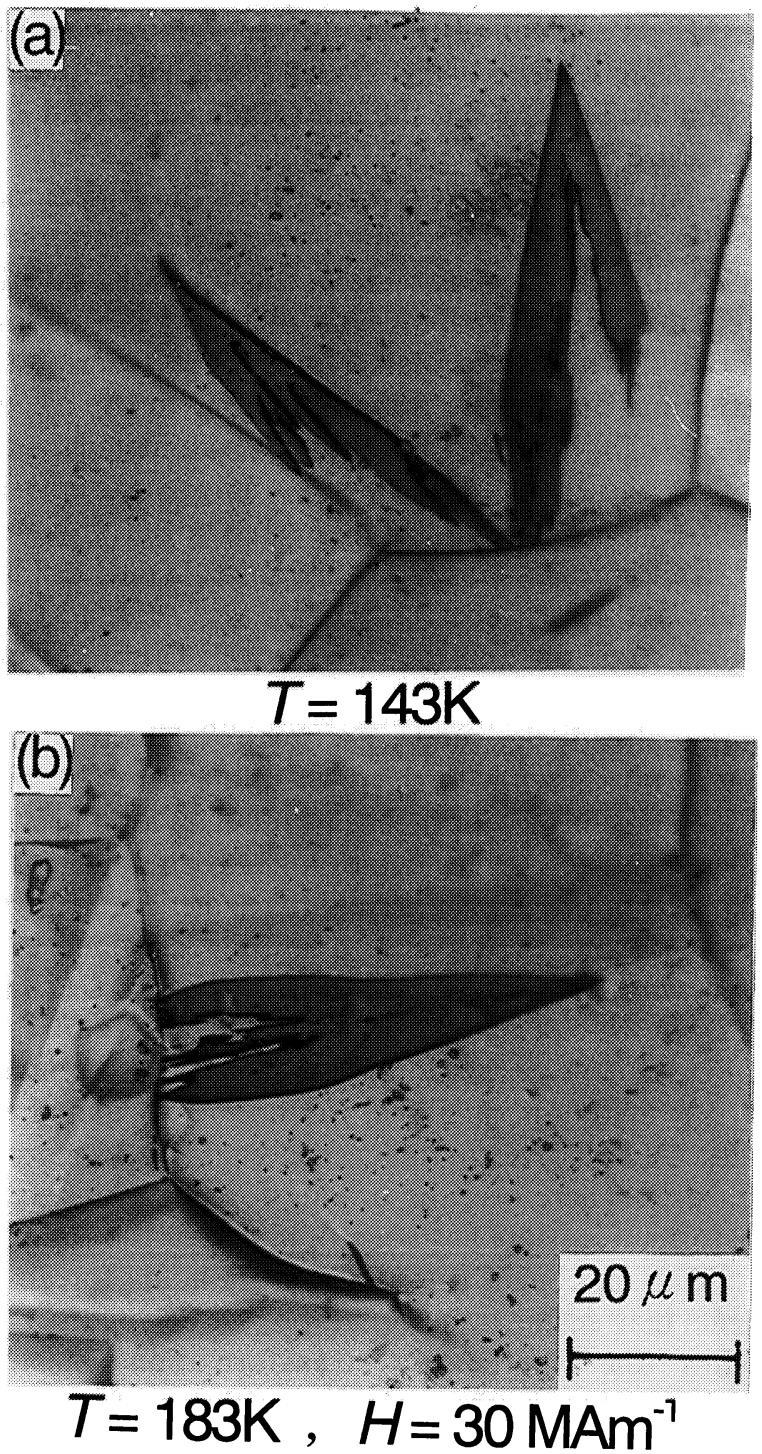

Fig. 12 Optical micrographs of thermally-induced martensites, (a), and magnetic field-induced martensites, (b), in an $\mathrm{Fe}-25.04 \mathrm{Ni}-4.0 \mathrm{Cr}$ (mass\%) alloy.

field susceptibility and forced volume magnetostriction effects $^{(8)}$. The following equation has been derived to estimate the relation between the critical magnetic field for inducing martensite and the transformation start temperature:

$$
\begin{aligned}
\Delta G\left(M_{\mathrm{s}}\right)-\Delta G(T)= & -\Delta M(T) \cdot H-(1 / 2) \cdot \chi_{\mathrm{h}}^{\mathrm{p}} \cdot H^{2} \\
& +\varepsilon_{0} \cdot(\partial \omega / \partial H) \cdot H \cdot B,
\end{aligned}
$$

where $\Delta G\left(M_{\mathrm{s}}\right)$ and $\Delta G(T)$ represent the difference in Gibbs chemical free energy between the austenite and martensite phases at the $M_{\mathrm{s}}$ and $T$ temperatures, respectively, $\Delta M(T)$ the difference in spontaneous magnetization between the austenitic and martensitic states at $T, H$ the magnetic field, $\chi_{\mathrm{h}}^{\mathrm{p}}$ the high magnetic field susceptibility in the austenite phase, $\varepsilon_{0}$ the volume change associated with martensitic transformation, $\omega$ the forced volume magnetostriction and $B$ the austenitic bulk modulus. The first, second and third terms on the right-hand side of eq. (1) represent energies due to the magnetostat- 
ic, high field susceptibility and forced volume magnetostriction effects, respectively. $H$ and $T$ satisfying the above equation are nothing but the critical magnetic field $H$ at temperature $T$.

Based on eq. (1), the relation between the critical magnetic field and the transformation start temperature has been calculated for the two alloys used, and the calculated relation was compared with the experimental one. First of all, we have calculated for the A alloy exhibiting an athermal martensitic transformation. In the calculation, $\Delta M(T), \varepsilon_{0}, \chi_{\mathrm{h}}^{\mathrm{p}}\left(\chi_{\mathrm{h}}^{\mathrm{p}}\right.$ is obtained from magnetization curve, as shown in Fig. 8) and $\omega$ among the physical quantities involved in eq. (1) were set to be the ones measured in the present study. On the other hand, the bulk modulus, $B$, of the austenitic phase was referred to the previous studies ${ }^{(12)}$ and the difference in Gibbs chemical free energy, $\Delta G(T)$, was calculated by referring to the equation already derived by Kaufman ${ }^{(13)}$. The result thus calculated is shown with the dashed line in Fig. 9, being in good agreement with the measured one, as in previous studies $^{(5)(10)}$. The same calculation has been made for the $B$ alloy exhibiting an isothermal martensitic transformation, by putting the physical quantities obtained in the present work and previously obtained $B$ and $\Delta G(T)$ into eq. (1). In the calculation, however, the driving force for making the transformation start, which corresponds to $\Delta G\left(M_{\mathrm{s}}\right)$ in an athermal one, can not be calculated even when $\Delta G(T)$ is given in this case, because no $M_{\mathrm{s}}$ temperature exists. Therefore, the driving force for making the transformation start has been obtained in the following way. That is, considering that eq. (1) holds for an isothermal martensitic transformation, the driving force for making the martensitic transformation start, $\delta$ (= $=\Delta G\left(M_{\mathrm{s}}\right)$ for an athermal martensitic transformation), may be written as

$$
\begin{aligned}
\delta= & \Delta G(T)-\Delta M(T) \cdot H-(1 / 2) \cdot \chi_{\mathrm{h}}^{\mathrm{p}} \cdot H^{2} \\
& +\varepsilon_{0} \cdot(\partial \omega / \partial H) \cdot H \cdot B .
\end{aligned}
$$

Thus, $\delta$ can be estimated by putting the measured critical magnetic field and other physical quantities into eq. (2), and the value thus obtained is $1786 \mathrm{~J} / \mathrm{mol}$ under the critical magnetic field of $17.5 \mathrm{MA} / \mathrm{m}$ at $163 \mathrm{~K}$, being much higher than $\Delta G(0)(1670 \mathrm{~J} / \mathrm{mol})$. This value is fixed during the calculation. The calculated critical magnetic field vs temperature relation is shown with a dotted line in Fig. 9, also being in good agreement with the experimen- tal one in the wide temperature range between 4.2 and $200 \mathrm{~K}$. This means that the effect of magnetic fields on the originally isothermal martensitic transformation also consists of three ones, magnetostatic, magnetic high field susceptibility and forced volume magnetostriction effects, which are cumulative, as in the athermal martensitic transformations examined so far ${ }^{(5)(10)}$. That is, eq. (1) holds for both the processes of martensitic transformations. These results mentioned in the present study are the same as those in $\mathrm{Fe}-\mathrm{Ni}-\mathrm{Mn}$ alloys previously examined, which also exhibits an athemal and/or isothermal martensitic transformation, depending on its alloy composition. Thus, we conclude from the present and previous results that the effect of magnetic field on athermal and isothermal processes has generality, that is, the isothermal process changes to the athermal process under a magnetic field and the relation between critical magnetic field and temperature is evaluated by using the eq. (1).

\section{Acknowledgments}

The present study was partly supported by the Grantin-Aid for fundamental Scientific Research (Ippann C, 1995, Jutenn, 1997) of Ministry of Education, Science, Sports and Culture, Japan. The supports are greatly appreciated.

\section{REFERENCES}

(1) G. V. Kurdjumov and O. P. Maksimova: Doklady Akad. Nauk SSSR., 61 (1948), 83.

(2) S. R. Pati and M. Cohen: Acta Metall., 17 (1969), 189.

(3) S. K. Gupta and V. Raghavan: Acta Metall., 23 (1975), 1239.

(4) S. Kajiwara: Mater. Trans. JIM, 33 (1992), 1027.

(5) T. Kakeshita, K. Kuroiwa, K. Shimizu, T. Ikeda, A. Yamagishi and M. Date: Mater. Trans. JIM, 34 (1993), 415.

(6) T. Kakeshita, K. Kuroiwa, K. Shimizu, T. Ikeda, A. Yamagishi and M. Date: Mater. Trans. JIM, 34 (1993), 423.

(7) T. Araki, K. Shibata, K. Asakura and H. Wada: Trans. Iron and Steel Inst. Jpn., 15 (1975), 175.

(8) T. Kakeshita and K. Shimizu: Proc. ICOMAT-86, Nara, Japan, p. 230.

(9) Physics in High Magnetic Fields, eds. S. Chikazumi and N. Miura: Springer, Berlin, (1981), p. 44.

(10) T. Kakeshita, K. Shimizu, S. Funada and M. Date: Acta Metall., 33 (1985), 1381.

(11) J. Grangle and G. C. Hallame: Proc. Ryo. Soc., A272 (1963), 119.

(12) G. Oomi and M. Mori: Physica, B119 (1983), 149.

(13) L. Kaufman: referred to Doctor Thesis by M. K. Korenko, MIT, Cambridge, USA, (1973), p. 72. 